\title{
Dr. Santos Palazzi Coll
}

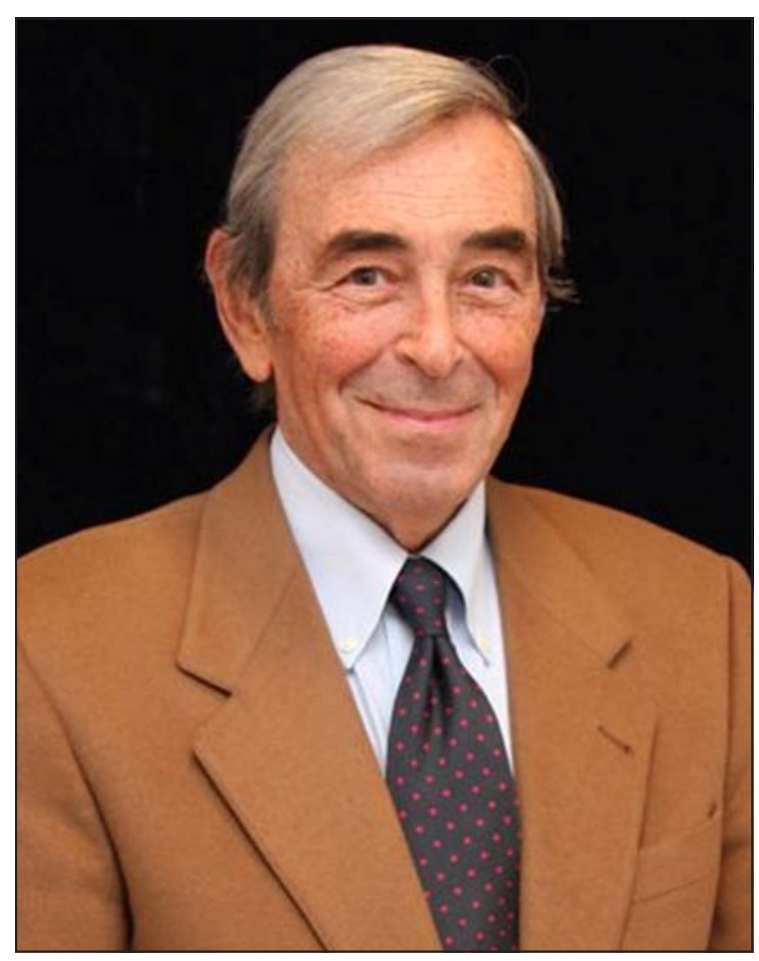

$\mathrm{N}$ ació en Roma en 1937. Hizo sus estudios de Medicina en la Facultad de Medicina de Barcelona (1961). Bajo la supervisión de su padre, Jefe de Servicio de Ortopedia del Hospital Sagrado Corazón de Barcelona, el mejor maestro que podía haber tenido, realizó la especialidad de Cirugía Ortopédica.

En 1967 inicia un período de formación en el Departamento de Cirugía Plástica y Reconstructiva de la Universidad Clínica de Viena, aprendiendo las técnicas de microcirugía vascular y nerviosa con el Profesor Millesi.

Posteriormente en 1970 visitó al Dr. C Scharizer en Manheimen en el Hand Surgery in Sports y en 1971 al Dr. JW Smith en el Hospital for Special Surgery, para mejorar las técnicas de microcirugía de los nervios periféricos.
Sin embargo, una de las personas que más influyo en él fue el Profesor Algimantas Narakas de Lausana, de quien aprendió a querer la patología del plexo braquial y su cirugía.

Después de la jubilación de su padre, es nombrado Jefe de Cirugía Ortopédica del Hospital Sagrado Corazón, donde permanece hasta el año 1993. Posteriormente continúa su actividad profesional en la Clínica Teknon de Barcelona.

El Dr. Santos Pallazi Coll es la persona de quien todos los cirujanos de la mano españoles han aprendido la cirugía del plexo braquial y de los nervios periféricos. Ha transmitido a todos sus conocimientos en una forma maravillosa, haciendo comprensible una materia tan difícil.

Actividades Relevantes:

Presidente del Simposio en Cirugía del Plexo Braquial. A. Narakas Club. Barcelona, 1999.

Presidente del $7^{\text {th }}$ Congress of the European Federation of Societies for Microsurgery. Euromicro 2004, Sitges, 2004.

Presidente de la Sociedad Española de Cirugía de la Mano (1985-1987).

Presidente de la Asociación Española de Microcirugía (1983-1985).

Presidente del Groupe pour l'Avancement de la Microchirurgie (1984-1986).

Miembro de la Sociedad Española de Cirugía de la Mano.

Miembro de la Sociedad Española de Cirugía Ortopédica y Traumatología.

Miembro de la Sociedad Internacional de Cirugía Ortopédica y Traumatología.

Miembro de la Sociedad Internacional de Microcirugía Reconstructiva.

Miembro correspondiente de la Sociedades de Cirugía Ortopédica y Traumatología de Venezuela y Argentina.

Miembro de la Real Academia de Cirugía de Cádiz. 